\title{
Desain Arsitektur dengan Penggabungan Ruang Hijau dan Fasilitas Publik
}

\author{
Anggraeni Retnoningtiyas dan Murni Rachmawati \\ Departemen Arsitektur, Fakultas Arsitektur, Desain, dan Perancangan, Institut Teknologi Sepuluh \\ Nopember (ITS) \\ e-mail:murnirarch@arch.its.ac.id
}

\begin{abstract}
Abstrak-Ruang terbuka hijau publik adalah RTH yang dimiliki dan dikelola oleh pemerintah daerah kota/kabupaten yang digunakan untuk kepentingan masyarakat secara umum. Syarat sebuah kota adalah memiliki $30 \%$ RTH dari luas wilayahnya, namun Kota Bekasi baru memenuhi $15 \%$ dari luas wilayahnya. Kota Bekasi sebagai kota penunjang ibukota Jakarta yang harus dapat mengimbangi terutama pada fasilitas publik. Ruang publik yang tersedia kurang diperhatikan dengan baik. Ruang publik seharusnya memberikan rasa nyaman dan rileks bagi penggunanya. Untuk itu dibutuhkan sebuah fasilitas ruang publik yang dapat menampung aktivitas masyarakat namun juga tidak menjadi bagian yang terpisah dari lingkungan sekitarnya. Metoda yang digunakan dalam perancangan fasilitas publik diatas adalah architecture as landscape methods untuk mendapatkan massa yang sesuai untuk menjawab permasalahan diatas, yaitu dengan menggabungkan ruang hijau dan fasilitas publik menjadi satu kesatuan. Pendekatan biophilik dipilih untuk memunculkan suasana nyaman pada objek rancang. Pendekatan biophilik dimasukan pada massa yang merupakan hasil dari metode yang telah dibuat sebelumnya.
\end{abstract}

Kata Kunci-Arsitektur, Architecture as Landscape, Ruang Publik, Ruang Hijau.

\section{PENDAHULUAN}

$\mathrm{R}$ UANG Terbuka Hijau (RTH) adalah area memanjang/jalur dan atau mengelompok, yang penggunaannya lebih bersifat terbuka, tempat tumbuh tanaman, baik yang tumbuh tanaman secara alamiah maupun yang sengaja ditanam. Ruang tebuka hijau publik adalah RTH yang dimiliki dan dikelola oleh pemerintah daerah kota/kabupaten yang digunakan untuk kepentingan masyarakat secara umum. Berdasarkan UU No. 26 tahun 2007 tentang Penataan Ruang, minimal 30\% dari luas wilayah kota harus berwujud ruang terbuka hijau [1]. Tercatat Kota Bekasi baru memiliki 15\% RTH yang tersebar di 23 kecamatan dan 56 kelurahan.

Kota Bekasi memiliki fasilitas yang kurang untuk memenuhi kebutuhan penghuni kota. Beberapa fasilitas ruang publik yang sudah terbangun juga kurang adanya perawatan yang optimal sehingga beberapa menjadi kurang layak fungsi yang akhirnya dapat mengganggu kenyamaan dan keamanan dari penggunanya sendiri. Beberapa ruang publik juga tidak memiliki fasilitas pendukung seperti toilet ataupun lahan parkir yang kurang memadai.

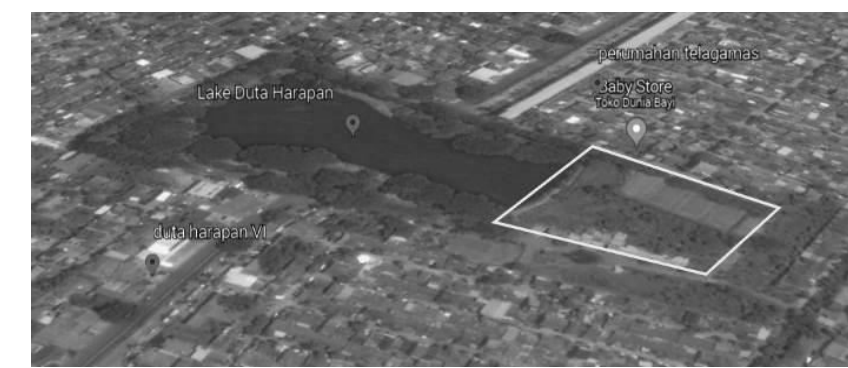

Gambar 1. Lahan rancangan.

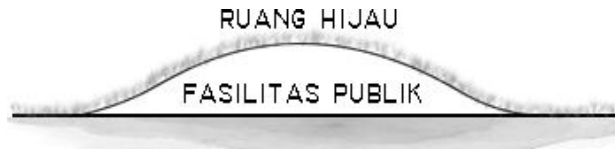

Gambar 2. Konsep utama.

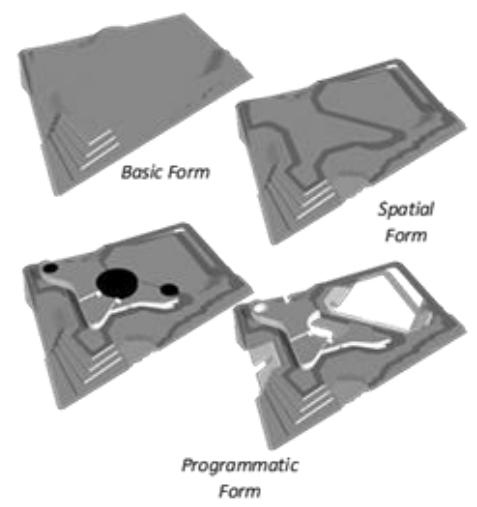

Gambar 3. Metoda desain.

Menurut Stephan Carr (1992), public Space ialah tempat dimana kehidupan komunal tercipta dan menjadi simbol komunitas yang terbentuk karena adanya kebutuhan akan tempat untuk bertemu atau berkomunikasi [2]. Ruang publik merupakan suatu wadah yang dapat menampung dan mendukung aktivitas manusia, baik untuk keluarga, kelompok, ataupun individu.

Objek rancangan merupakan ruang publik dan dapat meningkatkan nilai guna dari kawasan tersebut, dapat menyatu dengan zona RTH pada kawasan tersebut, dan dapat menciptakan aktivitas-aktivitas baru untuk masyarakat. Objek rancang tidak menambah persentase RTH kota namun menggabungkan ruang terbuka dengan fasilitas yang tetap terlindungi. 


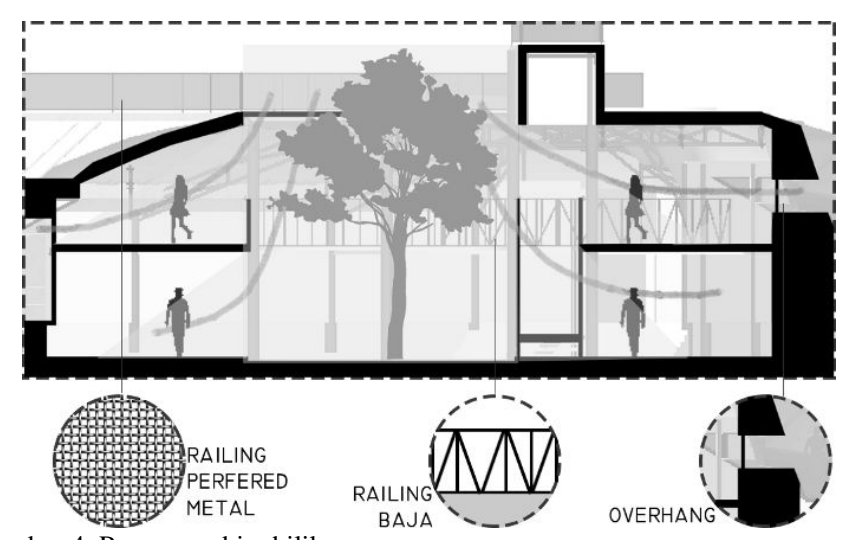

Gambar 4. Penerapan biophilik.

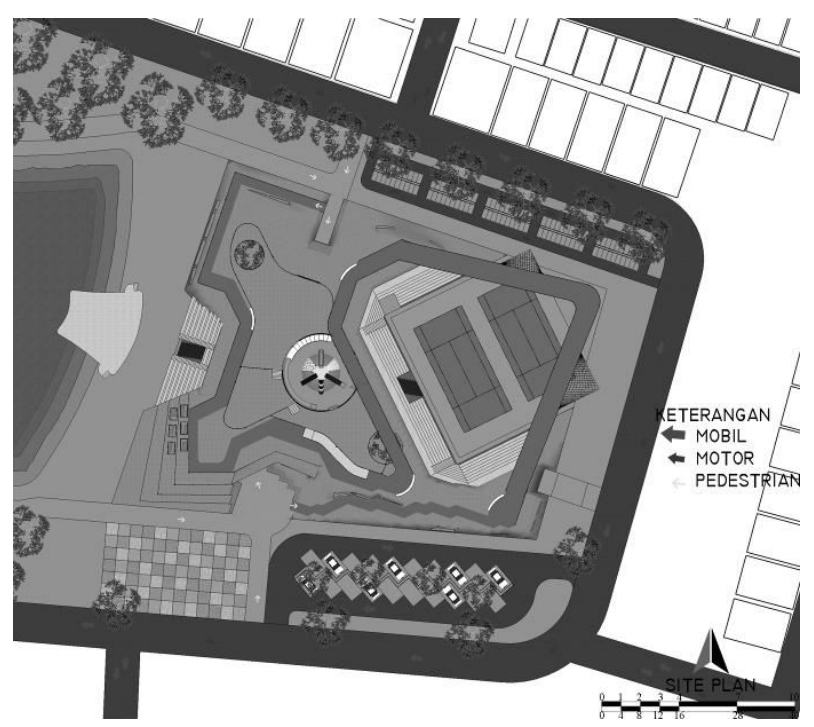

Gambar 5. Siteplan

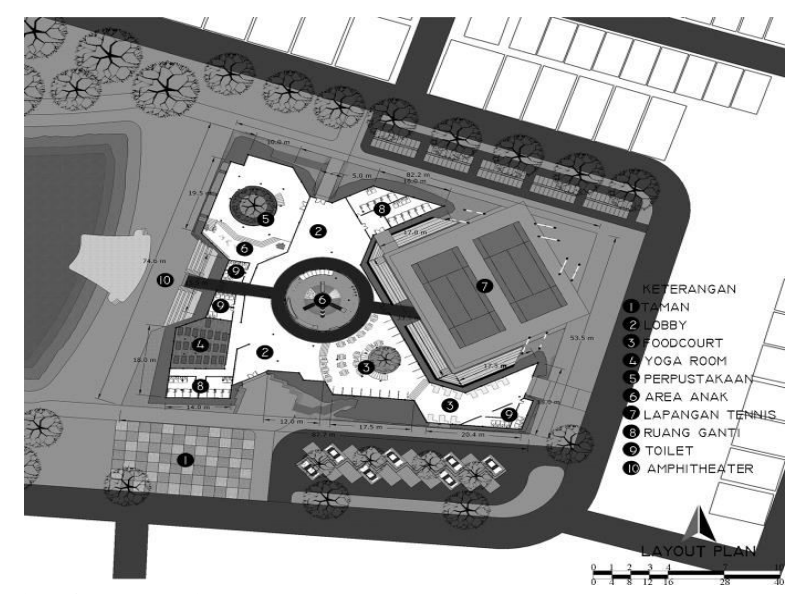

Gambar 6. Layout Plan

Lokasi lahan perancangan dipilih berdasarkan zona RTH pada rencana Perda Kota Bekasi tentang rencana detail tata ruang kota tahun 2011-2031 salah satunya berada di zona RTH rekreasi BWP Bekasi Utara, yaitu pada lokasi Danau Duta Harapan. Zona RTH tersebut terletak di sekeliling Danau Duta Utara, Harapan Baru, Bekasi Utara, Kota Bekasi [3]. Lokasi lahan perancangan merupakan salah satu ruang publik yang berada di Kota Bekasi.

Lahan perancangan (Gambar 1) berada di sebelah timur

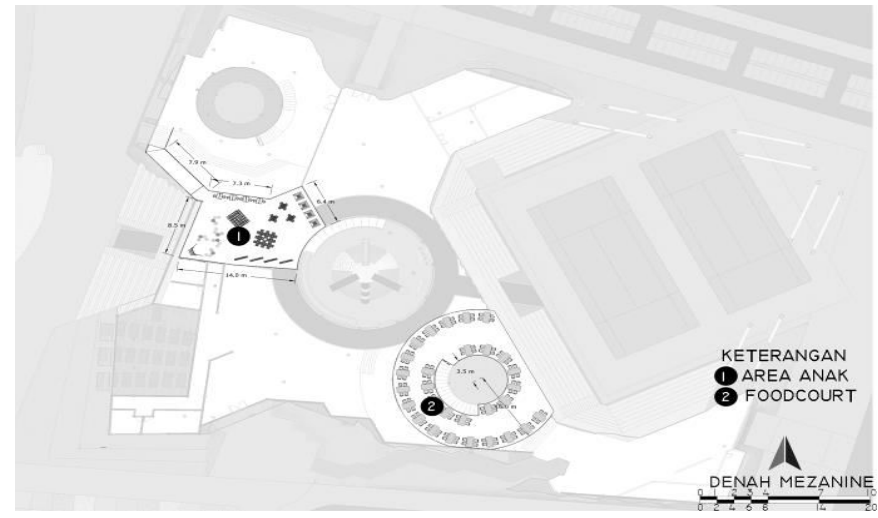

Gambar 7. Denah Mezzanine.

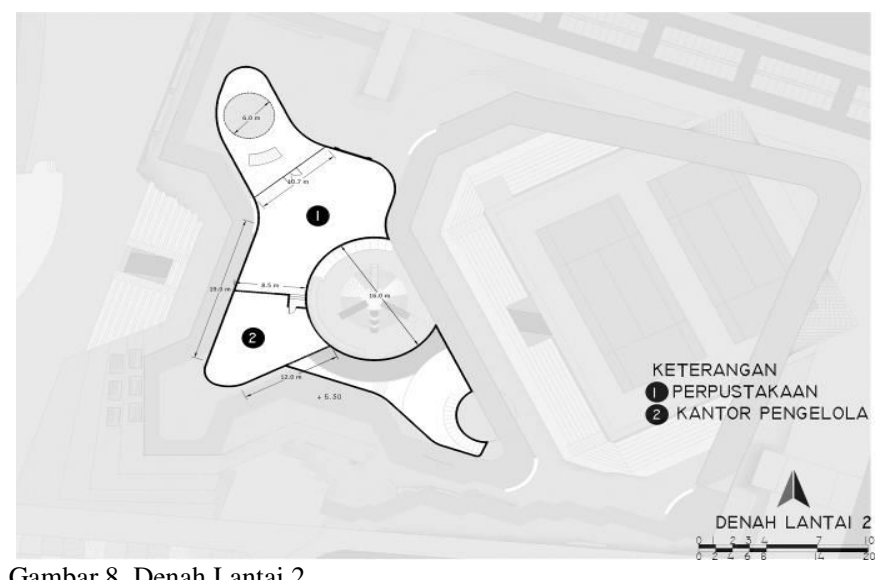

Gambar 8. Denah Lantai 2.

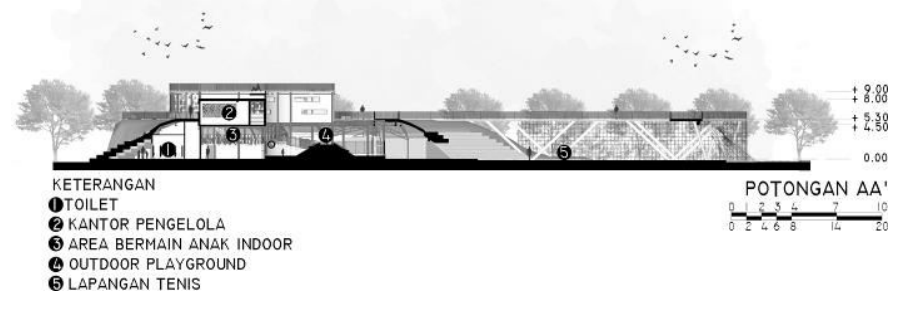

Gambar 9. Potongan AA.

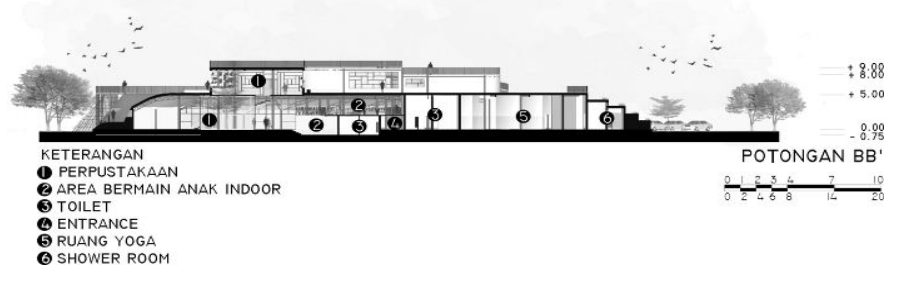

Gambar 10. Potongan BB.

danau dan merupakan lahan kosong yang tidak terawat dan bukan merupakan bagian dari RTH. Lokasi ini dipilih karena kawasan yang sudah dikenal dengan ruang terbuka hijau publik sehingga objek rancang dapat mampu meningkatkan nilai dari kawasan tersebut.

Masalah yang diselesaikan dalam perancangan ini adalah bagaimana sebuah ruang publik yang melindungi penggunanya namun juga sekaligus berperan sebagai ruang hijau? 


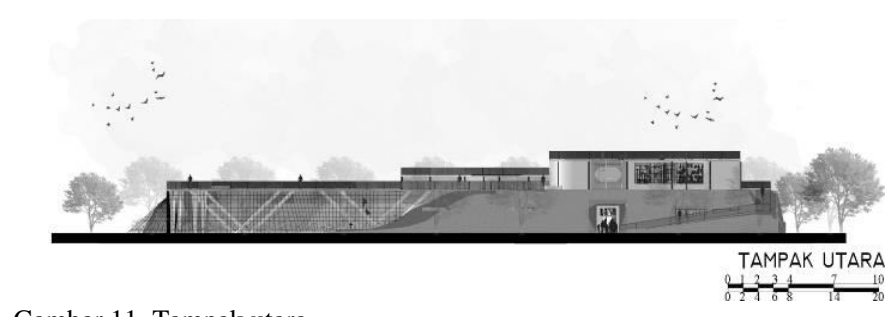

Gambar 11. Tampak utara.

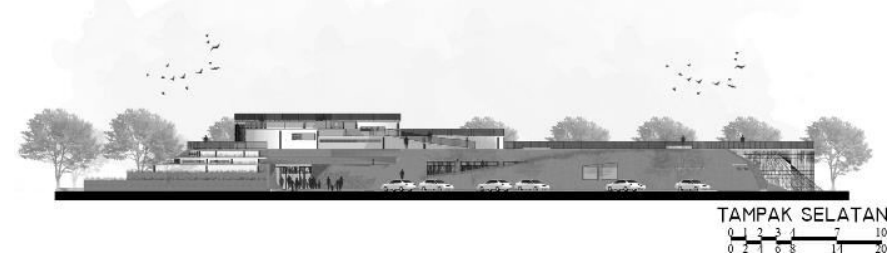

Gambar 12. Tampak Selatan.

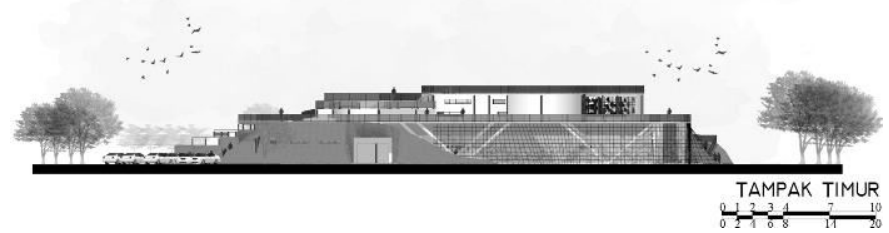

Gambar 13. Tampak timur.

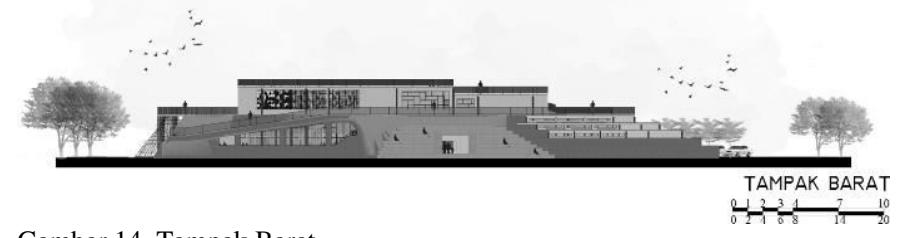

Gambar 14. Tampak Barat

\section{METODA PERANCANGAN}

Ruang publik yang baik seharusnya dapat membuat pengunjungnya nyaman dan dapat menjadi tempat relaksasi bagi penggunanya. Masyarakat yang terbiasa dengan Kota Bekasi yang ramai yang membuat ruang publik seharusnya menjadi tempat manusia dapat melarikan diri dari suasana melelahkannya. Oleh karena itu, desain ruang publik harus dirancang kondusif dengan memperhatikan efek psikologis pada manusia.

Biophilic dipilih sebagai pendekatan pada objek rancangan ini karena sesuai agar dapat mencapai ruang publik yang baik. Biophilic adalah kebutuhan biologis manusia untuk berhubungan dengan alam. Biophilik merupakan pendekatan desain berdasarkan ketertarikan atau ketergantungan secara ilmiah antara manusia dengan alam natural [4]. Desain biophilik adalah desain yang menghasilkan ruang yang dapat mereduksi stres, meningkatkan fungsi kognitif dan kreativitas dan meningkatkan kesejahteraan hidup manusia secara fisik dan mental.

Pendekatan biophilic terbagi menjadi 3 kategori yang selanjutnya melahirkan 14 pattern desain. Pada rancangan ini mengambil 3 pattern untuk diterapkan pada objek rancang. Pattern tersebut ialah visual connection with nature, thermal and airflow variability dan refuge.

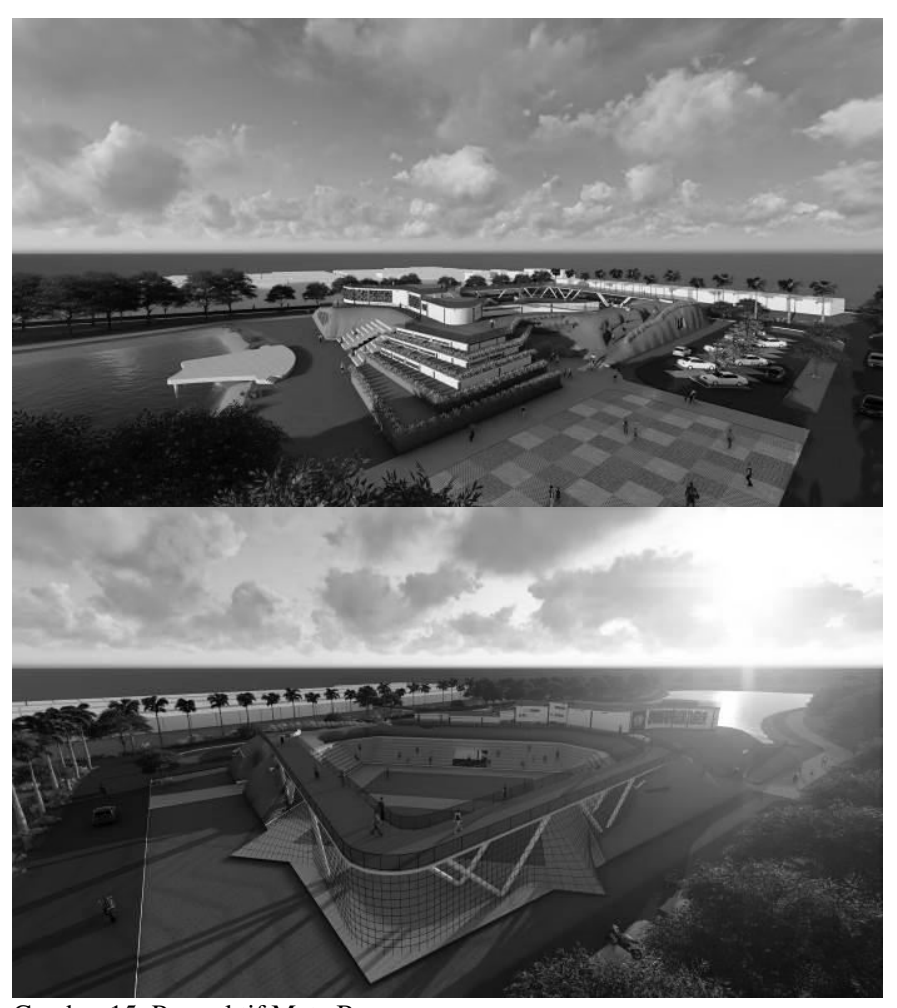

Gambar 15. Perspektif Mata Burung.

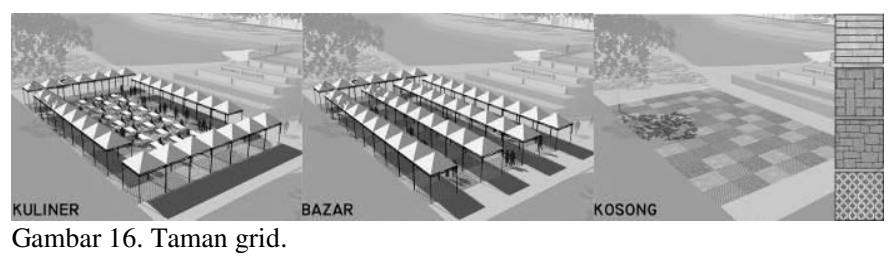

Konsep utama dari perancangan ini adalah fasilitas publik yang diselimuti dengan ruang hijau (Gambar 2). Metode desain yang digunakan dalam rancangan ini adalah Architecture as Landscape Methods oleh Daniel Jauslin (2010) [5]. Metode ini dipilih agar objek rancangan yang terbentuk tidak menjadi bagian yang terpisah dengan lingkungannya dan tetap dapat menampung aktivitas masyarakat pengguna ruang publik itu sendiri. Dalam metode ini proses merancang dibagi menjadi 3 tahap (Gambar 3):

1. Basic form adalah didefinisikan oleh hubungan dengan topografi sekitarnya dan topografi buatan terkait. Topografi buatan merupakan objek rancang itu sendiri.

Bentuk lahan yang datar maka desain diumpamakan sebagai bukit agar menjadi oase di tengah Kota Bekasi dan menjadi landmark dari kawasan tersebut. Panjang dan lebar massa dibuat mengikuti bentuk lahan yang kemudian bentuk massa dibuat bergelombang dengan ketinggian 3x tinggi manusia. Agar menyerupai bukit maka menggunakan green roof sehingga desain terlihat seperti ruang hijau dan fasilitas berada dibawahnya. Salah satu sisi dibuat terasering untuk menjadi aksen.

2. Spatial form adalah tentang pengalaman ruang lansekap. Menghubungkan ruang dalam dengan sekitarnya, jalur sirkulasi. 


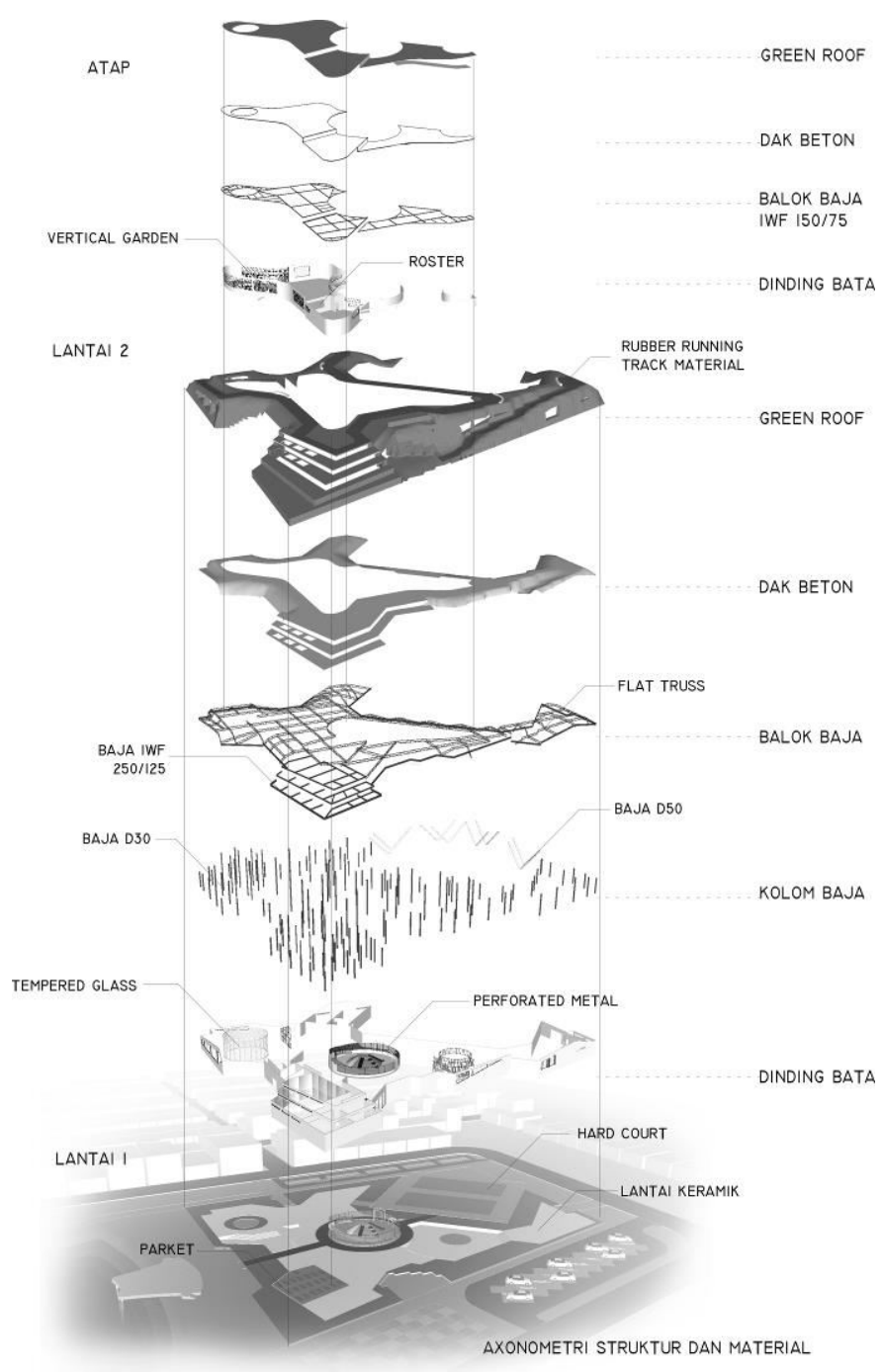

Gambar 17. Axonometri stuktur dan material.

Agar green roof tetap dapat dijangkau pengunjung maka dibuat sirkulasi menuju ke atap dengan menggunakan ramp. Sirkulasi pada atap dibuat mengelilingi bangunan dan ditambahkan jembatan agar semua sisi bangunan dapat di akses. Sirkulasi pada atap juga dimaksudkan untuk alur jogging track. Untuk sirkulasi masuk ke dalam bangunan dibuat lubang yang diumpamakan seperti masuk ke dalam goa.

3. Programmatic form adalah pembagian fungsi dan pengorganisasian hubungan ruang yang memperngaruhi komposisi.

Peletakkan program ruang menyesuaikan dengan sirkulasi yang telah dibuat sebelumnya. Tiap ruang harus mendapatkan udara dari luar maka tiap ruang diletakkan dengan dinding terluar. Zona anak menjadi fokus utama maka diletakkan ditengah ruang dengan membuat void besar sebagai outdoor playground yang merupakan titik pertemuan garis diagonal lahan untuk menentukan titik tengah bangunan. Void-void tambahan juga dibuat sebagai indoor garden.

Menambahkan mezzanine pada dalam ruangan pada aktivitas-aktivitas yang tidak memerlukan ruangan yang terlalu tinggi. Untuk mencapai tinggi ruang yang ideal, lantai pada bagian bawah mezzanine diturunkan.

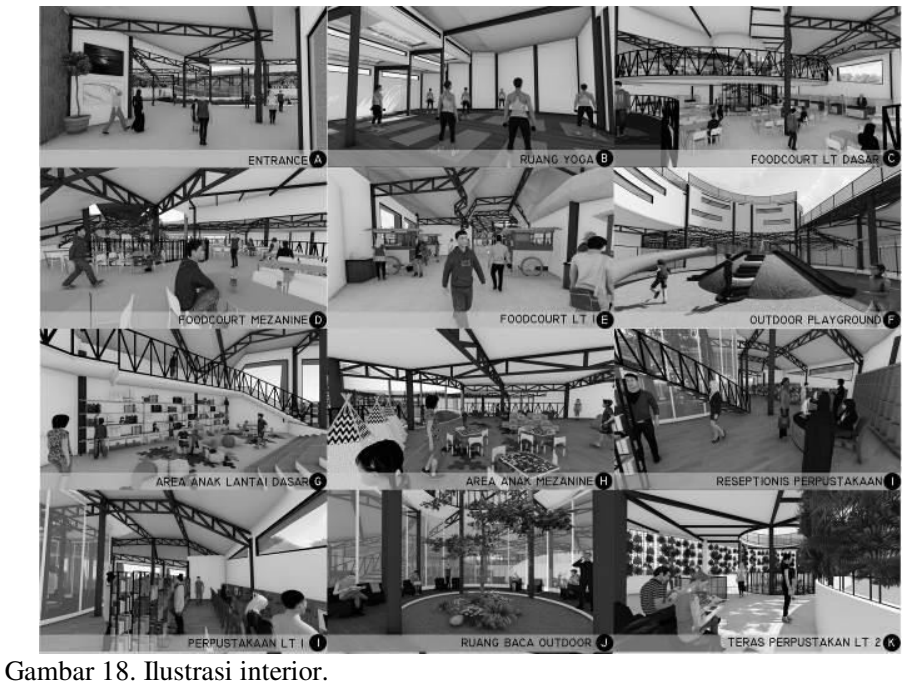

Untuk menambah luas area bangunan maka ditambahkan lantai 2 dan atapnya tetap dapat diakses pengunjung dengan tetap menggunakan green roof. Bentuk lantai 2 disesuaikan dengan sirkulasi yang telah ditentukan sebelumnya. Bagian yang tak berkontur dibawah digunakan sebagai lapangan tenis. Bagian lembah digunakan sebagai podium penonton untuk amphitheater dan lapangan tenis.

Penambahan lantai 2 mengakibatkan adanya penambahan sirkulasi untuk menju ke atap paling tinggi. Untuk menuju atap lantai 2 digunakan sirkulasi vertikal berupa ramp dan tangga. Atap lantai 2 dapat digunakan untuk tempat duduk-duduk atau piknik.

Dari bentuk yang sudah dibuat menggunakan metode diatas maka selanjutnya dengan pendekatan biophilic ditentukan bukaan-bukaan pada objek rancang. Bukaan-bukaan ini untuk masuknya udara dan cahaya matahari. Penentuan void-void sebagai indoor garden juga ditentukan berdasar pada pendekatan ini.

Void-void sebagai indoor garden menjawab pattern visual connection with nature dan thermal and airflow variabelity yaitu sebagai akses visual alam untuk penambah kenyamanan pengunjung dan sebagai jalur masuk udara dan sinar matahari ke dalam bangunan. Bukaan lebar juga dibuat untuk akses visual alam ke arah luar dan masuknya cahaya dan udara, selain itu juga berfungsi agar pengunjung di luar dapat melihat aktivitas di dalam bangunan. Overhang berfungsi untuk mengurangi panas dan melindungi dari hujan. Railing berfungsi untuk keamanan dan keselamatan pengguna. Keduanya menjawab pattern refuge. (Gambar 4)

\section{HASIL DAN EKSPLORASI}

Dengan menggunakan architecture as landscape methods dihasilkan rancangan yang menyerupai bentuk bukit. Penggunaan green roof pada selaput bangunan membuatnya terlihat sebagai ruang hijau yang dibuat lebih tinggi dari daerah sekitarnya sehingga pengunjung dapat dengan cepat melihat objek rancang.

Bentuk objek rancang mempengaruhi alur sirkulasi pada lahan sehingga peletakkan parkir dibagi 2 yaitu parkir mobil yang berdekatan dengan pintu masuk utama dan parkir motor 


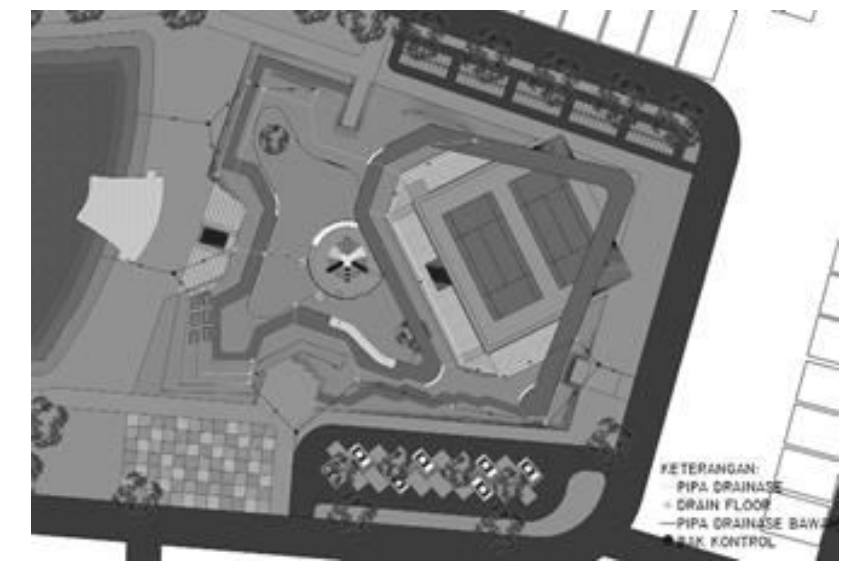

Gambar 19. Drainase.

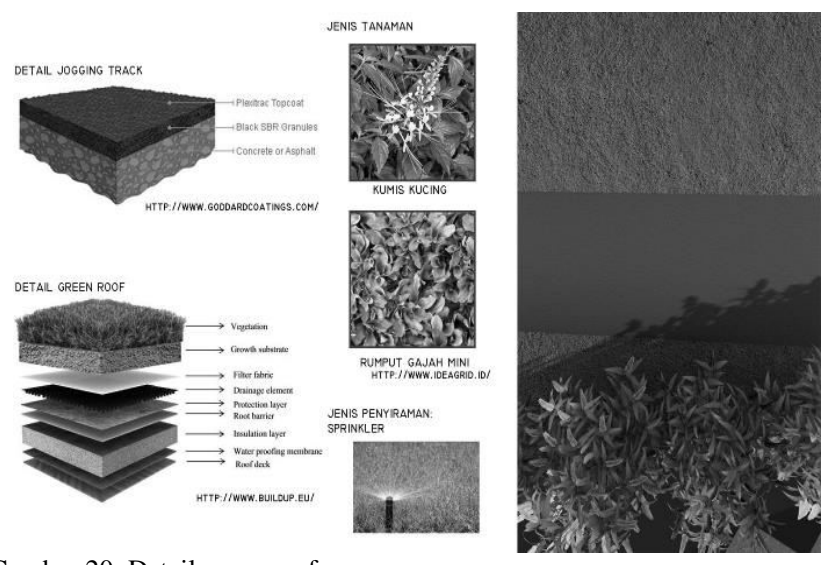

Gambar 20. Detail green roof.

seperti bangunan keluar dari bukit dibawahnya. (Gambar 1115)

Pada sisi barat parkir mobil dibuat taman dengan bentuk grid dan berpola dengan ukuran $2.5 \times 2.5 \mathrm{~m}$ yang dimaksudkan agar memiliki fungsi lebih dari sekedar taman. Ukuran tersebut disesuaikan dengan kebutuhan lebar stand. Material yang digunakan adalah grass blok dengar berbagai motif area bisa dimanfaatkan untuk bazar atau wisata kuliner. Pertimbangan pembuatan area ini karena pada weekend pagi pedagang di kawasan tersebut meningkat. Karena kawasan berada di pemukiman maka area dapat digunakan untuk acara 17an atau event lainnya. (Gambar 16)

Struktur bangunan menggunakan baja dengan balok flat truss yang bentuknya menyesuaikan dengan bentuk selaput bangunan yang telah dibuat. Sehingga bentuk tidak berubah namun beban tetap dapat tersalurkan dengan baik dan mampu mengatasi bentang lebar sehingga menghemat kolom. (Gambar 17)

Struktur pada lantai dasar dibuat terekspos memperlihatkan balok trus yang membentang. Stuktur bangunan yang diekspos dimaksudkan agar bagian interior tetap dapat merasakan atap bangunan yang tidak rata. (Gambar 18)

Pemilihan penggunaan green roof pada selaput bangunan mempengaruhi aliran drainase pada bangunan. Air dialirkan melalui pipa menuju danau atau saluran kota (Gambar 19). Hal ini juga mempengaruhi pemilihan jenis tanaman yang dapat tumbuh tanpa merusak struktur bawahnya (Gambar 20).

\section{KESIMPULAN}

Objek rancang menggunakan architecture as landscape methods untuk mendapatkan bentuk yang menyerupai elemen alam untuk mewujudkan ruang hijau agar terkesan menggantikan facant space yang digunakan sebagai lahan objek rancang. Sehingga kehadiran objek rancang seperti tidak menghilangkan kebutuhan ruang terbuka dari masyarakat.

Fasilitas publik diletakkan dibawah ruang hijau disesuaikan dengan kebutuhan masyarakat dan memasukkan pendekatan biophilik setelah mendapatkan bentuk dan zona ruang hasil dari metode agar pengguna merasa aman terlindungi dari panas dan hujan, serta aktivitas menjadi lebih nyaman. 
Dari luar objek rancang seperti menyatu dengan ruang luar dan pengguna dapat mengakses hingga ke titik tertinggi dari objek rancang.

\section{DAFTAR PUSTAKA}

[1] Peraturan Pemerintah Republik Indonesia, "UU RI No. 26 tahun 2007 tentang Penataan Ruang,” Jakarta, 2007.
M. A. Carr, S., Francis, M., Rivlin, G. L., \& Stone, Public Space. Australia: Press Syndicate of the University of Cambridge, 1992.

[3] Pemerintah Kota Bekasi, "Perda Kota Bekasi No. 13 tahun 2011 tentang Rencana Detail Tata Ruang Kota Bekasi 2011-2031," Bekasi, 2011.

[4] W. D. Browning, C. O. Ryan, and J. O. Clancy, 14 Patterns Of Biophilic Design: Improving Health \& Well-Being In The Built Environment. New York: Terrapin Bright Green, LLC, 2014. 